\title{
Efeitos toxicológicos desencadeados pelo etanol no organismo humano: uma revisão
}

Por motivos históricos, a utilização de bebidas alcoólicas tem se consolidado como um hábito comum na sociedade, fazendo com que o etanol se tornasse a droga psicoativa mais utilizada no mundo. Diversos estudos têm demonstrado que a interação do etanol e dos seus produtos metabólicos no organismo humano está vinculada a um conjunto de alterações fisiológicas que tornam o indivíduo suscetível a uma série de doenças, dentre elas, o câncer. Diversos mecanismos são descritos, destacando-se: o efeito depressor sobre o sistema nervoso; e a interferência em vias metabólicas, bem como o efeito dos metabólitos gerados sobre a estrutura da molécula do DNA, causando alterações covalentes que geram mudanças no padrão de expressão gênica. Além disso, o efeito do etanol sobre sistemas enzimáticos, como os citocromos P450, pode resultar em perda total ou parcial do efeito farmacológico, interferindo na terapêutica e originando produtos que causam danos teciduais. Dessa forma, devido à complexidade e multiplicidade de mecanismos envolvidos no dano celular desencadeado pelo etanol e seus produtos no organismo humano, este artigo apresenta uma revisão sistemática dos principais efeitos e mecanismos toxicológicos, bioquímicos e epigenéticos, evidenciados e descritos recentemente na literatura científica.

Palavras-chave: Etanol; Toxicologia; Metabolismo; Epigenética.

\section{Toxicological effects triggered by ethanol in the human body: a review}

\begin{abstract}
For historical reasons, the use of alcoholic beverages has established itself as a common habit in society, making ethanol the most used psychoactive drug in the world. Several studies have shown that the interaction of ethanol and its metabolic products in the human body is linked to a set of physiological changes that make the individual susceptible to a number of diseases, including cancer. Several mechanisms are described, highlighting: the depressant effect on the nervous system; and interference in metabolic pathways, as well as the effect of the metabolites generated on the structure of the DNA molecule, causing covalent changes that generate changes in the pattern of gene expression. In addition, the effect of ethanol on enzymatic systems, such as cytochrome P450, may result in total or partial loss of the pharmacological effect, interfering with the therapy and originating products that cause tissue damage. Thus, due to the complexity and multiplicity of mechanisms involved in the cellular damage triggered by ethanol and its products in the human body, this article presents a systematic review of the main toxicological, biochemical and epigenetic effects and mechanisms, evidenced and recently described in the scientific literature.
\end{abstract}

Keywords: Ethanol; Toxicology; Metabolism; Epigenetics.

Topic: Bioquímica

Reviewed anonymously in the process of blind peer.

Anderson José Gonzaga Lemos

Faculdade Guaraí, Brasil

http://lattes.cnpq.br/0660017521144164

bioander1986@hotmail.com

Simone Pôssas Andrade

Faculdade Guaraí, Brasil

http://lattes.cnpq.br/0552128506796918

simone.andrade@iescfag.edu.br

Mara Soares de Almeida Mota (iD

Faculdade Guaraí, Brasil

http://lattes.cnpq.br/3061777057739833

http://orcid.org/0000-0002-2068-3481

mara.almeida06@gmail.com
Received: 10/12/2017

Approved: 20/12/2017
Referencing this:

LEMOS, A. J. G.; ANDRADE, S. P.; MOTA, M. S. A.. Efeitos toxicológicos desencadeados pelo etanol no organismo humano: uma revisão. Scire Salutis, v.7, n.2, p.1-9, 2017. DOI: http://doi.org/10.6008/SPC2236$\underline{9600.2017 .001 .0001}$

DOI: 10.6008/SPC2236-9600.2017.002.0001 


\section{INTRODUÇÃO}

O etanol $\left(\mathrm{C}_{2} \mathrm{H}_{5} \mathrm{OH}\right)$, também denominado álcool etílico, é um composto orgânico que se apresenta como um líquido incolor, presente em todas as bebidas alcoólicas (KOOLMAN, 2005). As bebidas alcoólicas são líquidos destinados ao consumo humano que contêm em sua composição teores variáveis de etanol, com produção, distribuição e consumo permitidos por lei (ANDRADE et al., 2009). Sabe-se que a utilização de álcool pela humanidade remonta à pré-história, por volta de 2200 a.C., o que implica que o hábito de consumo de bebidas alcoólicas está intimamente arraigado na sociedade desde os primórdios das civilizações (BERTONI, 2006).

No Brasil, o processo de fermentação pelo qual suco de frutas, extratos ou tubérculos são acondicionados em ambiente anaeróbio ainda constitui a principal forma de obtenção desse produto (BARBOSA, 1998). Embora o álcool (etanol) seja reconhecido na literatura como uma droga de uso corrente, sua utilização tem sido interpretada como um hábito comum e aceitável, e isto de fato, tem dificultado o reconhecimento de determinados padrões de consumo e associações com doenças, bem como a mobilização de profissionais de saúde para a diminuição dos problemas gerados por seu uso indiscriminado (KOOLMAN, 2005; ANDRADE et al., 2009).

A utilização de álcool de forma indiscriminada também é conhecida por causar sérios impactos socioantropológicos, e entre esses, a dependência química, gravidez na adolescência, conflitos, agressões e acidentes automobilísticos, pois alteram consideravelmente a percepção sensorial e o padrão comportamental dos indivíduos (ANDRADE et al., 2009; BERTONI, 2006). Não obstante a este fato, o etanol e os seus produtos metabólicos estão vinculado a uma série de prejuízos à saúde do indivíduo, interferindo em importantes processos bioquímicos e fisiológicos que fazem com que o indivíduo se torne mais susceptível para o desenvolvimento de doenças (DEVLIN, 2006; KOOLMAN, 2005; MARZZOCO, 1999). Com base na relevância do tema, esse trabalho propõe a discussão acerca dos principais mecanismos envolvidos na indução de toxicidade pelo etanol e seus produtos metabólicos no organismo humano, com o objetivo propiciar informações atualizadas e concisas sobre o tema.

\section{METODOLOGIA}

O presente estudo foi elaborado a partir de uma revisão sistemática de artigos especializados e livrostexto, adotando vários critérios, como a consulta aos indexadores Science Direct, Pubmed e Cientific Electronic Library Online (Sciello). Para o levantamento de artigos, utilizou-se as palavras-chave 'etanol', 'toxicologia', "epigenética", "metabolismo", e seus respectivos equivalentes em língua inglesa 'ethanol', 'toxicology', 'epigenetics' e 'metabolism'. Depois de realizada a busca de dados online, foi feita uma seleção dos artigos que se adequavam ao tema proposto e que apresentavam informações atualizadas e concisas sobre a temática proposta. 


\section{DISCUSSÃO TEÓRICA}

\section{Absorção e distribuição do etanol}

Por motivos culturais, a ingestão de bebidas alcoólicas tem se consolidado como um hábito comum na maior parte da população, sendo típico o consumo residencial, a distribuição ou comercialização em eventos sociais e similares, o que tem contribuído com o aumento gradativo do número de consumidores de bebidas alcoólicas (ANDRADE et al., 2009). Tem-se demonstrado que cerca de $70 \%$ dos adolescentes residentes em grandes centros já fizeram uso ou experimentaram bebida alcoólica; além disso, o início do consumo entre adolescentes está ocorrendo de forma cada vez mais precoce (MALTA et al., 2011). Um dos grandes atrativos que propicia a procura desta droga é o fato de que o etanol tem a capacidade de gerar efeitos ansiolíticos e de desinibição comportamental, sendo a princípio, utilizada como uma substância de socialização (MALTA et al., 2011; ANDRADE et al., 2009).

Após a ingestão da bebida alcoólica, o processo de deglutição permite seu inexorável trajeto através do canal esofágico, sendo imediatamente conduzido para a cavidade estomacal, onde se iniciará o processo de absorção e posteriormente de distribuição corporal (KOOLMAN et al., 2005; DANGELO et al., 1997). Cerca de $25 \%$ do etanol ingerido é inicialmente absorvida a partir do estômago, enquanto que a maior parte da substância, 75\%, é absorvido pela mucosa duodenal (DEVLIN, 2006; KOOLMAN, 2005).

Muitas vezes, a ausência de bolo alimentar na luz gastrointestinal pode de fato favorecer o processo de absorção e elevar os níveis de alcoolemia em um curto período (KOOLMAN, 2005; DANGELO et al., 1997). Após atravessar as barreiras epiteliais, seguindo principalmente pela veia porta hepática, capilares sinusoides e veia cava inferior, o etanol chega a grande circulação, por onde é distribuído para todos os recônditos do organismo (CHASE et al., 2009; DANGELO et al., 1997).

De fato, aproximadamente $3 / 4$ de todo o organismo já estará disponível para a imediata captação do etanol disponível no sangue, principalmente os tecidos nervoso, muscular, adiposo e ósseo (ZHANG et al., 2011; KOOLMAN, 2005). Devido seu pequeno tamanho a molécula de etanol tem a capacidade de atravessar facilmente a bicamada fosfolipídica que compõem a membrana plasmática das células, por difusão simples, indo interpor-se no ambiente intracelular (MATSUMOTO et al., 2011; ZHANG et al., 2011; CHASE et al., 2009; ROBERTIS, 2006).

\section{Metabolismo hepático}

O fígado é o principal sítio de metabolização do etanol (KOOLMAN, 2005; DEVLIN, 2006; MARZZOCO et al., 1999). A localização anatômica desse órgão permite que a maior parte dos xenobióticos ingeridos ou absorvidos alcancem seu parênquima (DEVLIN, 2006; DANGELO et al., 1997). Na célula hepática existem duas enzimas específicas, que atuam na metabolização do etanol: a enzima citosólica (álcool desidrogenase) $(A D H)$, que converte etanol em acetaldeído; e a enzima mitocondrial (aldeído desidrogenase) (ALDH), que converte o acetaldeído gerado em acetato (DEVLIN, 2006). 
A atuação conjunta das enzimas ADH e ALDH são responsáveis pela conversão do etanol em acetato, que por sua vez pode ser utilizada para gerar acetil coenzima A (acetil-CoA), uma molécula rica em energia que pode ser utilizada na produção de adenosina trifosfato (ATP) pelo ciclo de Krebs. Adicionalmente, o acetil-CoA formado pela metabolização alcoólica pode ser utilizado para síntese de moléculas de colesterol e ácidos graxos. Em consequência deste fato, o consumo do etanol pode estar relacionado com a elevação dos teores de lipídeos no organismo (KOOLMAN, 2005; DEVLIN, 2006).

O valor nutricional do etanol corresponde a aproximadamente $7 \mathrm{Kcal} / \mathrm{g}$, desta maneira, o consumo de bebidas alcoólica representa ingestão adicional de calorias que sempre devem ser somadas àquelas da dieta (HASEBA et al., 2010; DEVLIN, 2006; MARZZOCO et al., 1999). No entanto, quando a ingestão de etanol é contínua, não há aproveitamento energético dessa substancia, por que nessas circunstâncias ocorre a ativação de vias alternativas de metabolização que não geram acetil-CoA, e portanto não produzem energia (DEVLIN, 2006; MARZZOCO et al., 1999). Verifica-se, conforme se nota na figura 1, a estrutura química condensada do etanol. Seu pequeno tamanho possibilita sua passagem através da bicamada lipídica que compõem as membranas celulares.

\section{$\mathrm{CH}_{3}-\mathrm{CH}_{2}-\mathrm{OH}$}

Figura 1: Estrutura química condensada do etanol.

\section{Hipoglicemia alcoólica}

A metabolização do etanol pelas enzimas hepáticas ADH e ALDH tem como consequência o aumento dos níveis da forma reduzida da coenzima nicotinamida adenina dinucleotídeo (NADH). Normalmente, os teores de $\mathrm{NAD}^{+}$(forma oxidada) no meio intracelular são maiores do que a de $\mathrm{NADH}$, porém, com a conversão de etanol a acetato, eleva-se o NADH celular (MARZZOCO et al., 1999). Para que os processos fisiológicos da célula não fiquem prejudicados pela pouca disponibilidade de $\mathrm{NAD}^{+}$, o piruvato gerado pelo quebra da glicose é convertido em lactato, através de uma reação que consome NADH e regenera NAD+ (MARZZOCO et al., 1999).

A conversão de piruvato em lactato, denominada fermentação lática, tem como empecilho o consumo substancial do piruvato celular, cuja disponibilidade seria importante para a manutenção da síntese endógena de glicose (gliconeogênese), desta forma, a diminuição do piruvato celular acaba causando interferência na via glinoneogênica, que induz a hipoglicemia (DEVLIN, 2006). Dependendo das condições metabólicas do indivíduo (desnutrição ou depleção de reservas corporais), a hipoglicemia pode tornar-se severa a ponto de induzir neuroglicopenia. Além disso, se houver considerável elevação dos teores de lactato no plasma sanguíneo (hiperlactatemia) bem como o aumento na produção de corpos cetônicos pelo fígado, poderá haver acidose, que associada ao quadro de hipoglicemia e neuroglicopenia pode levar o indivíduo ao estado de coma (ABRAHAM et al., 2011; MARZZOCO et al., 1999). 


\section{Efeitos do etanol sobre o sistema nervoso}

O etanol é um depressor primário do sistema nervoso central (SNC) (GOODMAN, 2003). Sua ação tóxica pode ocorrer em qualquer nível do neuroeixo, incluído encéfalo, nervos e músculos. O mecanismo de inibição das funções neurofisiológicas ligada ao consumo de álcool está relacionado com o aumento da ativação dos receptores para o ácido gama aminobutíruco (GABA) (DEVLIN, 2006; GOODMAN, 2003).

O GABA, é um dos principais neurotransmissores inibidores do SNC, cujo efeito se desencadeia pela interação com receptores específicos, que atuam como canais para o íon cloreto (HAES et al., 2010; GOODMAN, 2003). Quando GABA ativa os canais iônicos gabaérgicos, a abertura dos canais causa influxo de cloreto para o interior da célula neuronal, induzindo a polarização, ou seja, intensificação da negatividade da superfície interna da membrana neuronal. Uma vez presente no tecido nervoso, o etanol tem a capacidade de se ligar e ativar os receptores para GABA, determinando influxo exacerbado de cloreto para o meio intracitoplasmático, que causa hiperpolarização da membrana neural (MATSUMOTO et al., 2011; HAES et al., 2010; DEVLIN, 2006; GOODMAN, 2003).

A atuação depressora do etanol sobre o sistema nervoso é evidenciada pelos sintomas de intoxicação precoce, como euforia, alterações do estado de humor, desinibição social, rubor facial, taquicardia, midríase, perda da coordenação ou equilíbrio corporal e vertigens (GOODMAN, 2003). Caracteristicamente, indivíduos que ingerem bebida alcoólica habitualmente podem apresentar um limiar de tolerância elevado, de tal forma a permitir sobriedade em concentrações séricas acima de $100 \mathrm{mg} / \mathrm{dL}$. Em contrapartida, indivíduos não etilistas podem se sensibilizar aos efeitos neurodepressores com concentrações séricas de etanol em torno de 31 a 65mg/dl (HAES et al., 2010; CHASE et al., 2009).

Estudos com gêmeos tem demonstrado que a tendência ao consumo de álcool tem influência genética, existindo locus que são mais susceptíveis para o desenvolvimento da dependência química do que outros (ZAKHARI, 2013; MOROZOVA et al., 2012). O fato de o etanol inibir a gliconeogênese hepática levando o indivíduo a um estado de hipoglicemia faz com que seja importante à realização de exames para avaliação dos níveis glicêmicos em indivíduos intoxicados. Em caso de hipoglicemia (glicose plasmática <70mg/dl), a infusão de soro glicosado no paciente pode evitar agravos como neuroglicopenia, acidose e/ou coma. Sabese que os efeitos pós-embriaguez, vulgarmente conhecido como ressaca, são atribuídos ao acetaldeído, um metabólito do etanol gerado pela ação da ADH. (DEVLIN, 2006; GOODMAN, 2003; MARZZOCO et al., 1999).

\section{Biotransformação do etanol}

Os indivíduos que ingerem bebida alcoólica podem ser classificados em dois grupos: etillistas, que sofrem de dependência química e/ou psicológica, consumindo álcool de forma compulsiva; e bebedores ocasionais ou 'bebedores de finais de semana', que ingerem álcool em dias alternados, sem periodicidade. Em ambos os casos, a ingestão caracteristicamente contínua ou relativamente alternada está vinculada com o aumento da atividade de uma segunda via de metabolização, cuja atuação tem se mostrado com elevado 
potencial para o desencadeamento de danos oxidativos no organismo humano (CEDERBAUM, 2012; HAORAH et al., 2008; KOOLMAN, 2005; MARZZOCO et al., 1999).

Esta via de biotransformação do etanol é representado principalmente por heme-proteínas pertencente à família dos citocromos P450, encontrados predominantemente na bicamada fosfolipídica do retículo endoplasmático liso de hepatócitos e de células gastrointestinais. Entre outras funções, essas enzimas atuam na biotransformação química de compostos de origem exógena, como drogas, contaminantes e carcinógenos, que após processados, tornam-se mais solúveis e de fácil excreção pelo organismo. Estima-se que no organismo humano existam cerca de 30 tipos de enzimas pertencentes à família dos citocromos $\mathrm{P} 450$, sendo referidas pelo termo 'CYP' seguido por um número que se refere à família do citocromo, uma letra maiúscula que representa a subfamília, e um número terminal, que se refere à forma individual da enzima com base em suas sequências específicas de aminoácidos (DEVLIN, 2006).

O mecanismo de metabolização de xenobióticos via CYP se faz pela inserção de um átomo de oxigênio em uma reação denominada monoxigenação, que hidrossolubiliza o composto com o objetivo de facilitar sua eliminação pelas vias de excreção, conforme ilustrado pela figura 2. A metabolização do etanol por esta via é feita por uma CYP denominada 2E1 (dimetilnitrozamina-N-desmetilase), que tem como substrato, além do etanol, várias outras moléculas orgânicas, como outros álcoois, halogênios e alguns agentes anestésicos.

Tem-se demonstrado que ingestão de bebidas alcoólicas em um período de aproximadamente 6 - 7 horas aumenta a expressão de genes CYP e por conseguinte a síntese das moléculas de CYP2E1 em fígado e estômago. Como CYP2E1 pode biotransformar vários compostos orgânicos, incluindo fármacos, a utilização de medicamentos após à ingestão de bebidas alcoólicas muitas vezes está vinculada com a perca da eficácia farmacológica. (DEVLIN, 2006; GOODMAN, 2003).

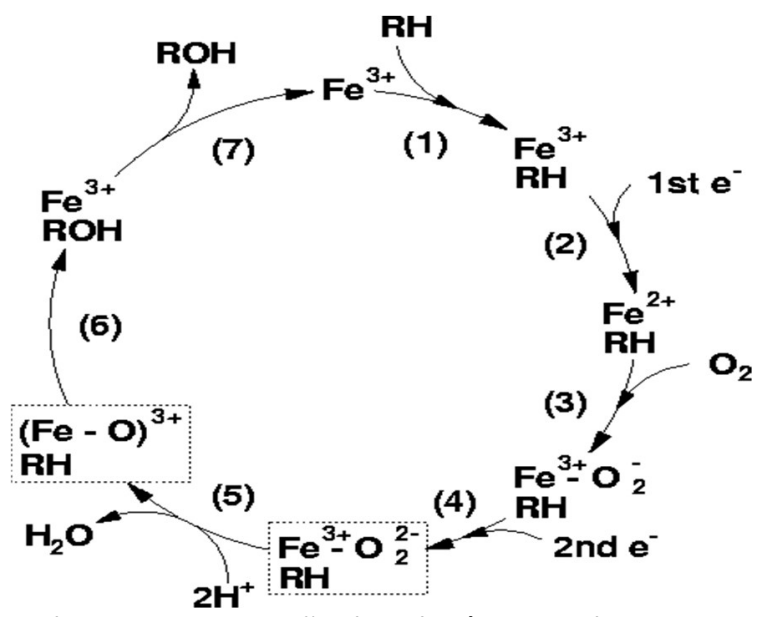

Figura 2: Esquema representando a monoxigenação de substâncias pelo citocromo P450. Esse processo ocorre principalmente em células do fígado e sistema gastrointestinal. Fonte: Lemos et al. (2014).

O paracetamol (acetaminofeno), por exemplo, quando administrado após ingestão de bebida alcoólica, tem seu efeito farmacológico diminuído por causa de sua acelerada metabolização pelas CYPE1 que foram induzidas pelo etanol. Normalmente, a metabolização do paracetamol se faz pelas vias comuns de glucuronidação e sulfatação; isso porque em condições fisiologicamente normais, isto é, na ausência de 
etanol, os níveis hepáticos de CYP2E1 são relativamente baixos. Além de interferir no efeito farmacológico, a atuação de CYP2E sobre o paracetamol leva a produção de um composto denominado N-acetil-pbenzoquinoneimina (NAPQ1), um substancia tóxica muito reativa que pode causar dano tecidual (LEMOS et al., 2014; DAM et al., 2009; DEVLIN, 2006; MARZZOCO et al., 1999).

\section{Etanol e epigenética}

O termo epigenética refere-se às modificações no padrão de expressão dos genes que não ocorrem por alterações nas sequências de bases desoxirribonucleotídicas de DNA, mas que podem, caracteristicamente, ser transmitidas ao longo das gerações (ZAKHARI, 2013; HASEBA et al., 2010). As modificações epigenéticas são determinadas por alterações químicas como metilação do DNA, bem como acetilação, ADP-ribosilação e/ou fosforilação em proteínas histônicas, afetando a estrutura e o grau de condensação da cromatina.

As primeiras evidências de que o etanol causa modificações epigenéticas no organismo foram demonstradas através da cultura de hepatócitos, onde se comprovou a ocorrência de acetilação em moléculas de histona $\mathrm{H} 3$, principalmente nos resíduos de lisina 4 e 9 da sua cadeia polipeptídica (ZAKHARI, 2013; HASEBA, 2010, ABRAHAM, 2011; DEVLIN, 2006). Em adição, observou-se que as modificações no padrão de acetilação da histona $\mathrm{H} 3$ não se restringem ao fígado, mas ocorrem também em vários outros tecidos do organismo.

Modificações em histonas induzidas por etanol estão associadas com alterações na expressão de vários genes, incluindo aqueles que codificam a enzima de metabolização do etanol (ADH), gene indutor de câncer (oncogene), e o gene que codifica uma proteína denominada plasminogênio inibidor do ativador 1 (PAl-1), que está envolvida na dispersão de coágulos sanguíneos em várias doenças como fibrose e alguns tipos de câncer (HASEBA et al., 2010; GOODMAN, 2003). A caracterização dos efeitos do etanol sobre as células do organismo humano é relativamente complexa pelo fato de sua metabolização ocorrer tanto por rotas oxidativas quanto por rotas não oxidativas, que resultam na geração de vários metabólitos diferentes (ZAKHARI, 2013; MOROZOVA et al., 2012; GOODMAN, 2003).

A acetilação das moléculas de histona H3 na cromatina, exercida pelo etanol e por seus metabólitos, foi demonstrado com a utilização de inibidores enzimáticos, como o 4-metilpirazol e a metilcinamida, que atuam como inibidoras das enzimas álcool desidrogenase e aldeído desidrogenase, respectivamente. Como esses inibidores foram possíveis observar que na ausência de formação de metabólitos do etanol (acetaldeído e acetato, por exemplo) ocorre uma considerável redução no grau de acetilação de histonas, sugerindo que o metabolismo do etanol tem um importante papel neste efeito. Outros achados sugerem que o acetato gerado a partir do etanol também poderia exercer acetilação em moléculas histônicas. (MOROZOVA et al., 2012; DEVLIN, 2006).

Outra consequência do metabolismo do etanol diz respeito à geração de espécies reativas de oxigênio (ROS); reactive oxygen species do inglês, que são compostos instáveis e extremamente reativos que 
podem causar alterações em várias biomoléculas, tais como o DNA, proteínas, carboidratos e lipídeos (ZAKHARI, 2013; MOROZOVA et al., 2012; KAPHALIA et al., 2011; HAORAH et al., 2008; GOODMAN, 2003). O efeito do etanol em desencadear alterações no padrão de metilação do DNA de células hepáticas também é evidenciado na literatura. Sabe-se que os genes que codificam as enzimas envolvidas no metabolismo do etanol (por exemplo, ADH) são regulados por processos de metilação. Dessa maneira, supõe-se que a redução do nível de metilação (hipometilação) do DNA causado pelo álcool etílico, tenha efeitos repressores nesses genes (HASEBA et al., 2010).

Em adição, observou-se que a ingestão crônica de etanol também pode afetar a metilação dos genes que regulam a absorção de ácido fólico pelas células da mucosa intestinal (ZAKHARI, 2013). Sabe-se que a deficiência de ácido fólico está vinculada a uma série de problemas, entre eles a elevação dos níveis de homocisteína no plasma, que é um fator de risco tanto para o desenvolvimento de doenças neurológicas quanto cardiovasculares (STEED et al., 2011; DEVLIN, 2006).

$\mathrm{Na}$ ingestão crônica de etanol, a hipometilação do DNA genômico em células da mucosa gastrointestinal constitui uma via que favorece a carcinogênese (ZAKHARI, 2013; HASEBA et al., 2010). Em adição, já é citada na literatura a inibição de sistemas proteolíticos induzidos pela presença do etanol, efeito este que pode interferir na eficiência do processamento de antígenos por células do sistema imune, bem como no processo de turnover proteico, que possibilita a renovação de moléculas proteicas em sistemas biológicos (KAPHALIA et al., 2011; OSNA et al., 2009; HAORAH et al., 2008)

\section{CONCLUSÕES}

Diante da multiplicidade de dados obtidos nos últimos anos, torna-se evidente o fato de que a ingestão de etanol está associada a uma série de eventos moleculares que estão direta ou indiretamente vinculados a gênese de várias doenças, bem como o estabelecimento de danos funcionais ou estruturais em células e tecidos. Além disso, devido à complexidade e amplitude dos efeitos desencadeados pelo etanol e seus produtos metabólicos no organismo humano, torna-se difícil o estabelecimento de uma dosagem de consumo conclusivamente segura, uma vez que o perfil metabólico e o polimorfismo genético influenciam nas respostas orgânicas individuais.

\section{REFERÊNCIAS}

ABRAHAM, J.; BALBO, S.; CRABB, D.; BROOKS, P. J.. Alcohol metabolism in human cells causes DNA damage and activates the Fanconi anemia: breast cancer susceptibility (FABRCA) DNA damage response network. Alcohol Clinical and Experimental Research, v.35, p.2113-2120, 2011.

ANDRADE, G. M.; ANTHONY, J. C.; SILVEIRA, C. M.. Álcool de suas consequências: uma abordagem multiconceitual. 1 ed. Barueri: Minha Editora, 2009.

BARBOSA, L. C. A.. Química orgânica. Viçosa: UFV ,1998.
BERTONI, L. M.. Reflexões sobre a História do Alcoolismo. Revista Fafibe On-Line, v.2, n.2, p.1-4, 2006.

CEDERBAUM, A. L.. Alcohol metabolism. Clinical Liver Disease, Hoboken, v.16, p.667-685, 2012.

CHASE, J. R.; POOLMAN, M. G.; FELL, D. A.. Contribution of $\mathrm{NADH}$ increases to ethanol's inhibition of retinol oxidation by human ADH isoforms. Alcohol Clinical and Experimental Research, v.33, p.571-580, 2009.

DAM, G.; SORENSEN, M.; MUNK, O. L.; KEIDING, S.. Hepatic ethanol elimination kinetics in patients with cirrhosis. 
Scandinavian Journal of Gastroenterology, v.44, p.867-871, 2009.

DANGELO, J. G.; FATTINI, C. A.. Anatomia humana básica. São Paulo: Atheneu, 1997.

DEVLIN, T. M.. Textbook of biochemistry with clinical correlactions, 6 ed. Hoboken: Wilwy-Liss Publication, 2006.

GOODMAN, L. S.; GILMAN, A. G.. As bases farmacológicas da terapêutica. 10 ed. Rio de Janeiro: McGraw-Hill, 2003.

HAES, T. M.; CLÉ, D. V.; NUNES, T. F.; RORIZ-FILHO, J. S.; MORIGUTI, J. C.. Álcool e sistema nervoso central. Medicina, Ribeirão Preto, v.43, p.153-163, 2010.

HAORAH, J.; RAMIREZ, S. H.; FLOREANI, N.; GORANTLA, S.; MORSEY, B.; PERSIDSKI, Y.. Mechanism of alcohol-induced oxidative stress and neuronal Injury. Free Radical Biology Medicine, Maryland, p.1542-1550, 2008.

HASEBA, T.; OHNO, Y.. A new view of alcohol metabolism and alcoholism: role of the high-Km class III alcohol dehydrogenase (ADH3). International journal of environmental research and public health, v.7, p.1076$1092,2010$.

KAPHALIA, B. S.. Pancreatic injury in hepatic alcohol dehydrogenase-deficient deer mice after subchronic exposure to ethanol. Toxicol Appl Pharmacol, Maryland, p.1-21, 2011.

KOOLMAN, J.; ROEHM, K. H.. Bioquímica, texto e atlas. Porto Alegre: Artmed, 2005.

LEMOS, A. J. G.; TRINDADE, E. J.. Interferências no efeito farmacológico mediadas pelas biotransformações dos citocromos P450. Revista Científica do ITPAC, Araguaína, v.7, n.2, 2014
MALTA, D. C.; MASCARENHAS, M. D. C.; PORTO, L. D.; DUARTE, E. A.; SARDINHA, L. M.; BARRETO, S. M.; NETO, O. L. M.. Prevalência do consumo de álcool e drogas entre adolescentes: análise dos dados da Pesquisa Nacional de Saúde Escolar. Revista Brasileira de Epidemiologia, v.14, 2011.

MARZZOCO, A.; TORRES, B. B.. Bioquímica básica. Rio de Janeiro: Guanabara Koogan, 1999.

MATSUMOTO, M.; CYGANEK, I.; SANGHANI, P. C.; CHO, W. K., LIANGPUNSAKUL, S.; CRABB, D. C.. Ethanol metabolism by HeLa cells transduced with human alcohol dehydrogenase isoenzymes: control of the pathway by acetaldehyde concentration. Alcohol Clinical and Experimental Research, v.35, p.28-38, 2011.

MOROzOVA, T.. The genetic basis of alcoholism: multiple phenotypes, many genes, complex networks. Genome biology, p.2-11, 2012.

OSNA, N. A.; WHITE, R. L.; THIELE, G. M.; DONOHUE, T. M. Ethanol metabolism alters major histocompatibility complex class i-restricted antigen presentation in liver cells.

Hepatology, v.49, p.1308-1315, 2009.

ROBERTIS, E. M. F.; HIB, J.. Bases da biologia celular e molecular. 4 ed. Rio de Janeiro: Guanabara Koogan, 2006.

STEED, M. M.; TYAGI, C. S.. Mechanisms of Cardiovascular Remodeling in Hyperhomocysteinemia. Antioxidants \& Redox Signaling, v.15, n.7, p.1927-1943, 2011.

ZAKHARI, S.. Alcohol metabolism and epigenetics changes. Alcohol research, v.35, p.6-16, 2013.

ZHANG, Y.; REN, J.. ALDH2 in alcoholic heart diseases: molecular mechanism and clinical implications. Pharmacol Ther, v.132, p.86-95, 2011. 